\title{
Assessment of weed establishment risk in a changing European climate
}

\author{
Terho Hyvönen ${ }^{a^{*}}$, Miska Luoto ${ }^{b}$ and Pertti Uotila \\ aMTT Agrifood Research Finland, Plant Production Research, FI-31600 Jokioinen, Finland

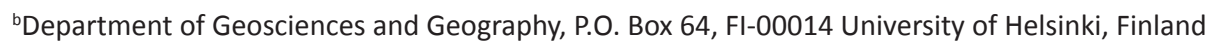 \\ 'Finnish Museum of Natural History, P.O. Box 7, FI-00014 University of Helsinki, Finland \\ *e-mail: terho.hyvonen@mtt.fi
}

\begin{abstract}
We aimed at assessing establishment risk for 25 arable weed species in a changing European climate for the period 2051-2080. An increase (0.3-46.7\%) in the range size was projected for the 14 species and a decrease (1.2-67.4\%) for the 11 species in a future climate. The inclusion of the land use data increased the explanatory power of the models. The greatest increases in range sizes were projected for Amaranthus retroflexus, Papaver hybridum and Fumaria parviflora, and declines for Sinapis arvensis, Cerastium semidecandrum and Chenopodium rubrum. Application of a more severe climate scenario (HadCM3A2) affected decline (0.5-18.5\%) for 12 species and increase $(2.2-31.5 \%)$ for 13 species in the range size projections compared with the less severe (HadCM3B2) scenario. Both model scenarios projected high percentage species loss in Mediterranean and temperate Europe, but high species gain in the Alps, Carpathians and in boreal Europe. The results suggest that even under moderate climate scenarios drastic changes in the weed establishment risk can be expected to take place in Europe in future.
\end{abstract}

Key words: arable weed, climate change, climate envelope modelling, global warming

\section{Introduction}

Adaptation of agricultural production to climate change requires information on the future risks faced by production systems. One of the risks for cropping systems is a range expansion of arable weeds (e.g. Patterson 1995, McDonald et al. 2009). The first step in the risk assessment of weed range expansion is predicting the probability of successful establishment of weed species by matching climate data.

The response of plants to climate change varies among species, depending on adaptation to specific climate conditions. Species adapted strictly to certain climate conditions may lose those conditions and face increase in extinction risk in a changing climate (Root et al. 2003, Thuiller et al. 2005). In contrast, species most likely to benefit from climate change in terms of extending range sizes are those with distributions independent of specific climate conditions and land use patterns (Hyvönen et al. 2011). Weed species are typically effective in dispersal and can maintain marginal populations outside their main ranges, i.e., they occur as casual aliens (see Richardson et al. 2000). Climate change could facilitate the establishment of such populations and thus extension of species range into new climate zones.

The south-north climate gradient in Europe comprises the Mediterranean, temperate, boreal and arctic zones. Arable weed species richness declines from south to north along this gradient (Holzner and Immonen 1982, Glemnitz et al. 2006). The same pattern occurs for several noxious weed species (Schroeder et al. 1993, Milberg and Andersson 2006, Hyvönen et al. 2011), which are of particular interest from a weed management perspective, although the distribution of most harmful weed species is practically ubiquitous in Europe (Glemnitz et al. 2006). Projections for the range shifts of European plant species due to climate change have indicated that the greatest species losses will occur in Mediterranean regions and the least in boreal, northern Alpine and Atlantic regions (Bakkenes et al. 2002, Thuiller et al. 2005). The greatest species gain is expected for the boreal region (Sætersdal et al. 1998, Bakkenes et al. 2002, Thuiller et al. 2005), which suggests that plant species of the temperate region could survive in the boreal region in future. Since these projections are based on a representative sample of the European flora, including several weed species, the same patterns can also be assumed for arable weeds. However, weed establishment risk at the European scale is needed to verify this assessment.

In the present study, weed establishment risk in Europe was assessed by modelling the changes in distribution of suitable climate conditions ("climate envelope", which is based on the current distribution of species) for weed species in a changing climate. This approach, known as climate envelope modelling (e.g. Pearson and Dawson 2003, Heikkinen et al. 2006), has proved useful for predicting the potential distribution of plants on a European 
scale (Bakkenes et al. 2002, Thuiller et al. 2005). These models are useful "first filters" for identifying locations that may be at greater risk and provide first approximations for impact of climate change on weed species ranges. However, previous attempts to apply climate envelope modelling for predicting the range size changes of arable weeds are few (Kriticos et al. 2005, Potter et al. 2009). For the present study we selected 25 weed species, representing species with southern and central European distribution patterns and different statuses as weeds, to assess weed species distribution by climate envelope modelling at European scale. The projections for individual species, as well as for the species assemblage, were calculated. The projections were produced for two climate scenarios differing in severity and with and without land use since previous studies have shown that the severity of the climate scenario (e.g. Thuiller et al. 2005) and land use (e.g. Luoto et al. 2007) affect range sizes. We posed three questions: 1) How does the weed establishment risk vary in Europe? 2) How does the inclusion of land use affect on the model performance? 3) How does severity of the climate scenario affect the establishment risk? We expected the establishment risk to be highest in northern Europe, the importance of land use to vary between species and the establishment risk to differ between climate scenarios.

\section{Material and methods \\ Plant data}

The distributional data for weed species were obtained from volumes 1-11 of Atlas Florae Europaeae (AFE) (Jalas and Suominen 1972-1994, Jalas et al. 1996, see Uotila et al. (2005) for the details of the Atlas project). Volumes 1-11 cover the first 68 families in the Englerian taxonomic sequence adopted by Flora Europaea, including angiosperms from Salicaceae to Cruciferae. An electronic database (Lahti and Lampinen 1999) was used to construct a data matrix indicating the presence or absence of each taxon in the 4420 UTM grid squares in which records are mapped in the Atlas. The size of most of the grid squares is $50 \mathrm{~km} \times 50 \mathrm{~km}$, but compensation zones occur along every 6 th meridian of longitude and here the width of squares ranges from 40 to $60 \mathrm{~km}$.

In total, 25 species were included in the analysis. The selection of weed species for the study was conducted in three phases. Firstly, all species regarded as arable weeds (302 species) based on the information obtained from Williams (1982) and Hanf (1983) were selected among all the AFE plant species (2794 species). Secondly, the species were ranked according to their importance as arable weeds based on Williams (1982) and the data obtained from a Europe-wide weed survey (Glemnitz et al. 2006). Thirdly, the final selection of species (25 species) was conducted by experts of weed distribution and management (T. Hyvönen and M. Glemnitz) to reach a species assemblage representing different kinds of distribution patterns of species and importance for the different kinds of crops (see Appendix 1). All plant observations (presence/absence) from the AFE database whose status was uncertain ('record uncertain as regards identification and/or locality') as well as extinct ('extinct' and 'probably extinct') were excluded. Therefore, the final data was organized into the following categories: 'introduced (established alien)', '(establishment) status unknown or uncertain' and 'native occurrence (incl. archaeophytes)'. Species representing different categories were treated equally in the analyses.

\section{Climate data}

Climate data were obtained from the Climatic Research Unit (CRU) climatological database (New et al. 2002, Mitchell et al. 2004). Averages for the time period 1961-1995 ('present-day' climate) were interpolated from the original $0.5 \times 0.5^{\circ} \mathrm{spatial}$ resolution to the $30 \times 60 \mathrm{~min}$ grid to match the species data, and used for calibrating the models. In our analysis we used three climate variables that reflect principal limitations on plant species growth: annual daily temperature sum above $5^{\circ} \mathrm{C}$, mean temperature of the coldest month (January) and water balance. Water balance was calculated as the monthly difference between precipitation and potential evapotranspiration, and by summing the individual monthly differences. The potential evapotranspiration (PET) was calculated following Skov and Svenning (2004):

$$
\mathrm{PET}=\frac{58.93 \times \mathrm{T}_{\mathrm{above} 0^{\circ} \mathrm{C}}}{12}
$$

This is a simple but widely used index that requires only monthly average values of temperature and precipitation (Skov and Svenning 2004). 
The future climate, which we contrasted with the 'present-day' climate, was the projected mean for the period 2051-2080. Thus, we used aggregated mean values of the same three climate variables for the period 2051-2080, based on the climate data from the two scenarios, HadCM3A2 (more severe) and HadCM3B2 (less severe), also derived from the CRU climatological database and interpolated to match the plant species data grid system. The more severe scenario (medium-high emission scenario) describes a very heterogeneous world with a continuously increasing population and regionally oriented economic development. Global concentrations of $\mathrm{CO}_{2}$ are projected to increase from 380 ppm in 2000 to 700 ppm in 2080, and temperature to increase by 2.8K (IPCC 2001). The less severe scenario (medium-low emission scenario) describes a world in which the emphasis is on local solutions to economic, social and environmental sustainability. Concentrations of $\mathrm{CO}_{2}$ are projected to increase from $380 \mathrm{ppm}$ in 2000 to $550 \mathrm{ppm}$ in 2080, and global temperature to increase by $2.1 \mathrm{~K}$.

\section{Land use data}

We extracted the data on land use (agricultural and urban) for each of the $50 \mathrm{~km} \times 50 \mathrm{~km}$ grid cells from the Global Land Cover 2000-Europe database ('GLC-Europe dataset'; see http://dataservice.eea.europa.eu/dataservice/ metadetails.asp?id=955). This dataset is a pan-European classification system that is consistent for the whole of Europe at a resolution of $1 \mathrm{~km}$.

\section{Modelling}

An increasingly popular approach in bioclimate envelope modelling is generalized additive models (GAM), which have been used in climate change impact studies by, for example, Leathwick et al. (1996), Thuiller (2003) and Araújo et al. (2004). GAMs are non-parametric extensions of generalized linear models (GLM). Using GAM and data on current climate, land use, species distributions and two different climate scenarios (HadCM3A2 (more severe) and HadCM3B2 (less severe)) for the period 2051-2080, we developed projections of the currently suitable area and potential range size changes of 25 European weed species. The focus in the GAM was both in the range shifts of the single species as well as the weed assemblage of 25 species. For weed assemblage, we calculated species loss (Loss $=100 *$ modelled loss / modelled current species richness, i.e. number of species in each grid cell), gain (Gain $=100 *$ modelled gain / modelled current species richness) and turnover (Turnover $=100 *$ (loss + gain) / (modelled current species richness + modelled gain). We calculated losses of climatically suitable areas assuming no migration, and gains and turnover assuming universal migration. Universal migration was used since weeds are typically highly mobile species and they colonize areas very rapidly. The estimations of species loss, species gain and species turnover were compared between the outcomes of different climate scenarios in order to determine whether these estimates are critically sensitive between the different scenarios.

The models were evaluated in two ways. First, the explanatory power of the model was assessed by examining the amount of the explained deviance (i.e. the ratio of explained deviance vs. total deviance) in each of the model calibration datasets. Second, following Lehmann et al. (2002), the predictive power of the model was examined based on the fourfold cross-validation statistics. A cross validation was made with subsets of the entire data set, where each subset contains an equal number of randomly selected data points. Each subset was then dropped from the model, the model was recalculated and predictions were made for the omitted data points. A combination of the predictions from the different subsets was then plotted against the observed data (Lehmann et al. 2002). Predictive power was measured using the area under the curve (AUC) of a receiver operating characteristic plot (Fielding and Bell 1997). The differences between the explained deviance and AUC values of the climate-only and climate-land use models were tested by the nonparametric Wilcoxon's signed rank test. All species distribution models and their validations were performed with GRASP 3.3 (Lehmann et al. 2002) for S-PLUS (Insightful Corporation, Seattle, WA, USA).

Then, the option provided by GRASP was used to evaluate quantitatively the importance of environmental predictor variables for each distribution model. GRASP calculates the sole contribution (the variable on its own, i.e. in a univariate model), the drop contribution (i.e. calculating the marginal increases in deviance when the variable is dropped from the full model) of each variable and the model contribution (i.e. the contribution of each predictor within the selected models) (Lehmann et al. 2002). For each predictor, the model contribution is defined by the possible range of variation on the linear predictor scale (Maggini et al. 2006). Here, all three types of contributions were used in scrutinizing the relative importance of different environmental variables as suggested by Maggini et al. (2006). 


\section{Results \\ Model performance with and without land use}

The inclusion of the land use data increased the explanatory power of the models (the amount of deviance explained) for all 25 weed-climate models (Wilcoxon's signed rank test, $Z=162.5, p<0.001$ ) and the AUC crossvalidation accuracy of 20 models out of 25 (Wilcoxon's signed rank test, $Z=152.5, p<0.001$ ) (Table 1). The explained deviance of climate-land use models averaged $27.6 \%$ and the predictive power (AUC) of the models ranged between 0.753 and 0.904 (Table 2), indicating good model performance. The climatic variables explained more of the variation of the models of individual species (except three species) than the land use (Fig. 1).

Table 1. Modelling accuracy [mean and standard deviation ( $\mathrm{min}-\mathrm{max}$ )] for the climate-only and climate-land use models measured by the amount of explained deviance and cross-validated AUC values. The differences between the mean values of the two types of models were tested with a Wilcoxon signed rank test. Ranks: negative/positive. Negative rank = the number of times when a climate-land use model was superior to a climate-only model, positive rank vice versa.

\begin{tabular}{lll}
\hline & Explained deviance & AUC cross-validation \\
\hline Climate-only & $0.253 \pm 0.077(0.138-0.443)$ & $0.814 \pm 0.041(0.739-0.899)$ \\
Climate-land use & $0.276 \pm 0.072(0.163-0.466)$ & $0.824 \pm 0.038(0.753-0.904)$ \\
Z & 162.5 & 152.5 \\
P-value & $<0.001$ & $<0.001$ \\
Ranks & $0 / 25$ & $4 / 20$ \\
\hline
\end{tabular}

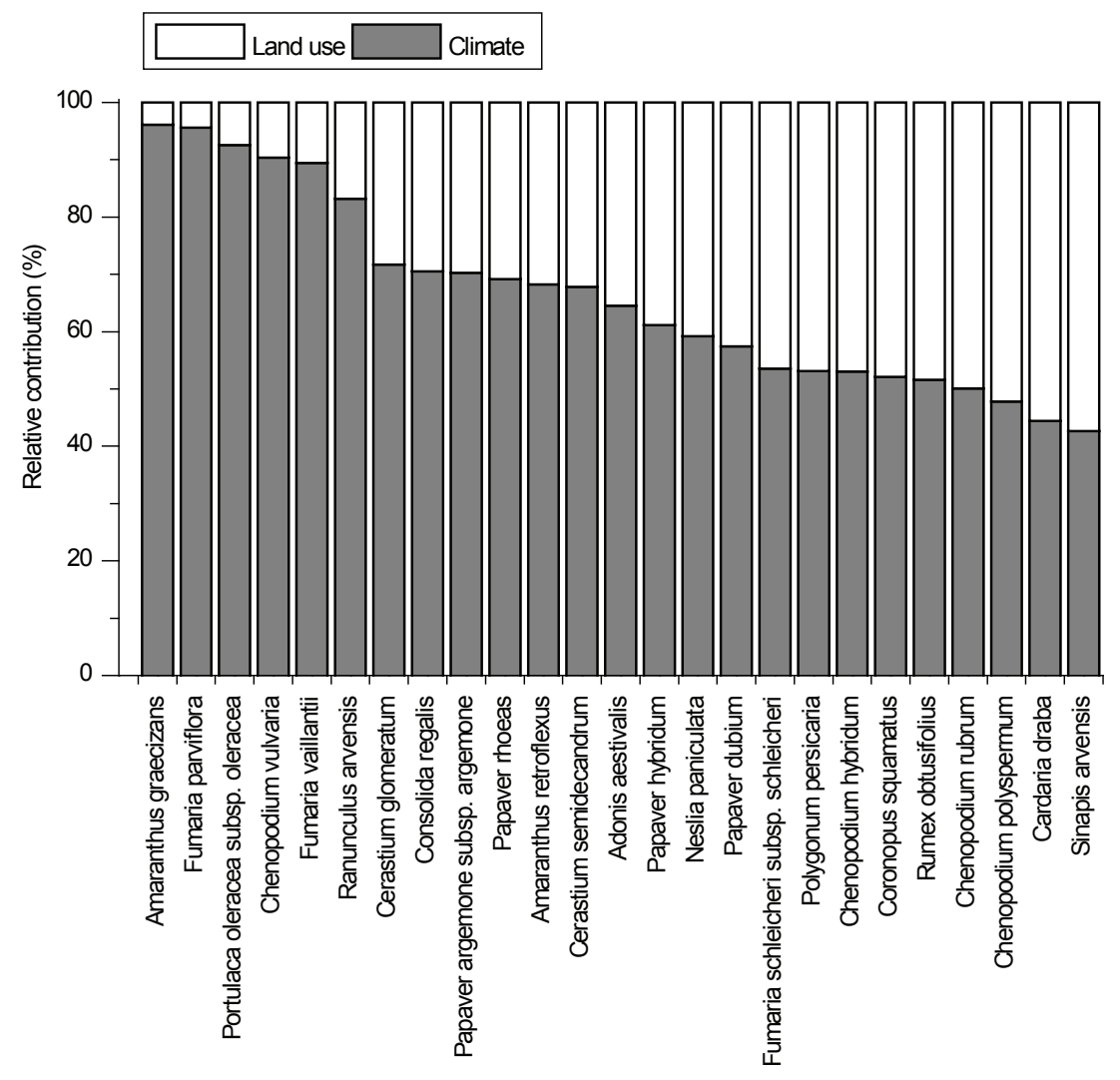

Fig. 1. The relative contribution (\%) of climate and land use variables on the distribution of 25 European weed species in GAM models based on current climate and land use data. See Appendix 2 for the more detailed information. 
Table 2. Prevalence, explained deviance and AUC values (based on four-fold cross-validation) of the studied 25 weed species based on climate only (C-model) and climate-land use (CLU-model) models utilizing multivariate generalized additive modelling (GAM) under the assumption of more severe (HadCM3A2) climate change scenario.

\begin{tabular}{|c|c|c|c|c|c|}
\hline Species & Prevalence & $\begin{array}{l}\text { Explained } \\
\text { deviance } \\
\text { C-model }\end{array}$ & $\begin{array}{l}\text { Explained } \\
\text { deviance } \\
\text { CLU-model }\end{array}$ & $\begin{array}{l}\text { AUC-value } \\
\text { C-model }\end{array}$ & $\begin{array}{l}\text { AUC-value } \\
\text { CLU-model }\end{array}$ \\
\hline Adonis aestivalis & 0.218 & 0.289 & 0.302 & 0.835 & 0.838 \\
\hline Amaranthus graecizans & 0.161 & 0.262 & 0.268 & 0.811 & 0.81 \\
\hline Amaranthus retroflexus & 0.473 & 0.204 & 0.221 & 0.792 & 0.797 \\
\hline Cardaria draba & 0.507 & 0.248 & 0.279 & 0.822 & 0.838 \\
\hline Cerastium glomeratum & 0.526 & 0.293 & 0.318 & 0.840 & 0.851 \\
\hline Cerastium semidecandrum & 0.488 & 0.138 & 0.171 & 0.740 & 0.765 \\
\hline Chenopodium hybridum & 0.366 & 0.250 & 0.270 & 0.828 & 0.831 \\
\hline Chenopodium polyspermum & 0.454 & 0.200 & 0.225 & 0.797 & 0.802 \\
\hline Chenopodium rubrum & 0.360 & 0.142 & 0.194 & 0.746 & 0.77 \\
\hline Chenopodium vulvaria & 0.346 & 0.231 & 0.237 & 0.802 & 0.801 \\
\hline Consolida regalis & 0.369 & 0.287 & 0.301 & 0.837 & 0.845 \\
\hline Coronopus squamatus & 0.347 & 0.272 & 0.302 & 0.821 & 0.831 \\
\hline Fumaria parviflora & 0.194 & 0.374 & 0.379 & 0.873 & 0.877 \\
\hline Fumaria schleicheri subsp. schleicheri & 0.109 & 0.443 & 0.466 & 0.899 & 0.904 \\
\hline Fumaria vaillantii & 0.283 & 0.279 & 0.288 & 0.838 & 0.837 \\
\hline Neslia paniculata & 0.395 & 0.139 & 0.163 & 0.739 & 0.753 \\
\hline Papaver argemone subsp. argemone & 0.346 & 0.228 & 0.270 & 0.809 & 0.831 \\
\hline Papaver dubium & 0.508 & 0.207 & 0.236 & 0.797 & 0.81 \\
\hline Papaver hybridum & 0.202 & 0.378 & 0.392 & 0.874 & 0.881 \\
\hline Papaver rhoeas & 0.627 & 0.333 & 0.371 & 0.856 & 0.874 \\
\hline Polygonum persicaria & 0.605 & 0.190 & 0.222 & 0.783 & 0.795 \\
\hline Portulaca oleracea subsp. oleracea & 0.335 & 0.287 & 0.290 & 0.837 & 0.835 \\
\hline Ranunculus arvensis & 0.418 & 0.285 & 0.304 & 0.828 & 0.836 \\
\hline Rumex obtusifolius & 0.568 & 0.198 & 0.224 & 0.784 & 0.795 \\
\hline Sinapis arvensis & 0.677 & 0.158 & 0.195 & 0.766 & 0.783 \\
\hline Mean ( \pm S.D.) & $0.395 \pm 0.150$ & $0.253 \pm 0.077$ & $0.276 \pm 0.072$ & $0.814 \pm 0.041$ & $0.824 \pm 0.038$ \\
\hline
\end{tabular}

In the modelling of individual species distributions, both less severe models projected increases in the distribution area for 14 of the 25 species (Table 3). A similar projection was reached with the more severe climate only model. The inclusion of land use in the model projected increase in the distribution area for 13 species and decrease for 12 of the 25 species (Table 3). The greatest declines in the range sizes were projecetd for Sinapis arvensis, Cerastium semidecandrum, Chenopodium rubrum and Papaver argemone (Table 3), whereas the greatest increases were projected for Amaranthus retroflexus, Papaver hybridum and Fumaria parviflora.

The inclusion of land use in the individual species models reduced the projected distribution area for most species (17 and 18 of 25 in less and more severe models, respectively, Table 3). The greatest declines (>20\%) were found for Polygonum persicaria, Rumex obtusifolius and Sinapis arvensis (Fig. 2, Table 3). The greatest increase in distribution area (around 3\%) was for Chenopodium polyspermum (Fig. 2, Table 3).

\section{Model performance with different climate scenarios}

When the climate scenario was changed from less to more severe, about half of the species (13 of 25) showed an increase in the projections for distribution areas (Table 3). The greatest increases in the projections for distribution area were detected for Amaranthus retroflexus (18.5\% and 18.4\% for pure climate and climate and land use models, respectively (Fig. 3), Papaver hybridum (16.0\% and 14.6\%) and Fumaria parviflora (15.8\% and 13.3\%). The greatest decreases 
in the distribution areas were projected for Sinapis arvensis $(31.5 \%$ and $25.3 \%$ for pure climate and climate and land use models, respectively (Fig. 3)), Cerastium semidecandrum (25.0\% and 27.2\%), Cerastium glomeratum ( $23.4 \%$ and $24.7 \%$ ), Papaver argemone (22.3\% and $30.3 \%$ ) and Chenopodium rubrum (21.2\% and $28.9 \%$ ) (Table 3 ). Overall, the change in the scenario from less severe to more severe increased the variance of the 25 species projections (Table 3 ).

Table 3. Results of the modelled distribution of the 25 weed species. Change in distribution shows the percentage change between the current projected distribution and that of the latter period(s) based on climate only (C-model) and climate-land use (CLU-model) models utilizing multivariate generalized additive modelling (GAM) under the assumptions of less (HadCM3B2 (B2)) and more (HadCM3A2 (A2)) severe climate change scenarios.

\begin{tabular}{|c|c|c|c|c|}
\hline \multirow[b]{2}{*}{ Species } & \multicolumn{4}{|c|}{ Change in distribution (\%) 2051-2080 } \\
\hline & B2 C-model & B2 CLU-model & A2 C-model & A2 CLU-model \\
\hline Adonis aestivalis & 3.1 & 2.0 & -1.2 & -3.0 \\
\hline Amaranthus graecizans & 18.8 & 19.3 & 25.3 & 25.9 \\
\hline Amaranthus retroflexus & 26.2 & 26.2 & 44.6 & 44.6 \\
\hline Cardaria draba & 23.0 & 15.3 & 29.3 & 21.6 \\
\hline Cerastium glomeratum & -21.4 & -21.4 & -44.8 & -46.2 \\
\hline Cerastium semidecandrum & -28.4 & -37.2 & -53.4 & -64.3 \\
\hline Chenopodium hybridum & -2.4 & -2.2 & -7.5 & -5.6 \\
\hline Chenopodium polyspermum & -3.0 & -0.3 & -8.4 & -5.1 \\
\hline Chenopodium rubrum & -19.5 & -32.0 & -40.7 & -60.9 \\
\hline Chenopodium vulvaria & 18.8 & 20.1 & 25.2 & 26.6 \\
\hline Consolida regalis & 6.4 & 5.7 & 11.0 & 11.8 \\
\hline Coronopus squamatus & 19.3 & 13.8 & 21.6 & 14.5 \\
\hline Fumaria parviflora & 29.4 & 26.3 & 45.3 & 39.6 \\
\hline Fumaria schleicheri subsp. schleicheri & -1.5 & -2.0 & 0.3 & -1.5 \\
\hline Fumaria vaillantii & 4.1 & 3.6 & 2.0 & 0.4 \\
\hline Neslia paniculata & 8.7 & 10.8 & 15.5 & 17.6 \\
\hline Papaver argemone subsp. argemone & -18.3 & -29.7 & -40.6 & -60.0 \\
\hline Papaver dubium & -1.5 & -15.7 & -16.9 & -42.5 \\
\hline Papaver hybridum & 30.8 & 26.5 & 46.7 & 41.1 \\
\hline Papaver rhoeas & 29.9 & 18.3 & 34.0 & 22.8 \\
\hline Polygonum persicaria & -5.8 & -27.9 & -20.5 & -49.2 \\
\hline Portulaca oleracea subsp. oleracea & 23.2 & 23.2 & 31.2 & 30.9 \\
\hline Ranunculus arvensis & 25.3 & 21.3 & 32.8 & 31.3 \\
\hline Rumex obtusifolius & -5.0 & -27.6 & -25.7 & -46.4 \\
\hline Sinapis arvensis & -11.3 & -42.0 & -42.8 & -67.4 \\
\hline Mean ( \pm S.D.) & $6.0 \pm 17.8$ & $-0.2 \pm 22.4$ & $2.5 \pm 31.4$ & $-4.9 \pm 37.7$ \\
\hline
\end{tabular}

Based on the more severe climate change scenario and (current) land use, species loss averaged $22.8 \%$, whereas the gain was $23.4 \%$ and turnover $39.2 \%$. The less severe climate change scenario and land use gave the following projections: $11.8 \%, 16.2 \%$ and $26.0 \%$, respectively. Models of both scenarios projected high percentage species loss in Mediterranean and temperate Europe, but high species gain in the Alps and Carpathians, as well as in boreal Europe (Figs. 4 and 5). 
A

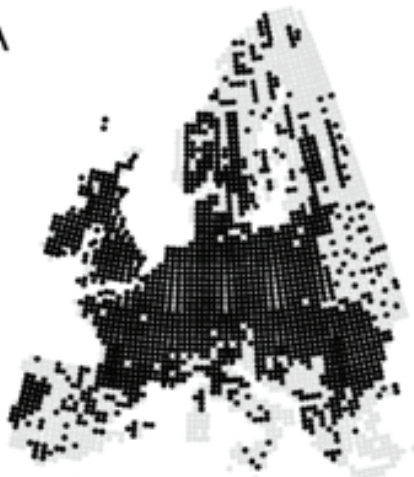

D

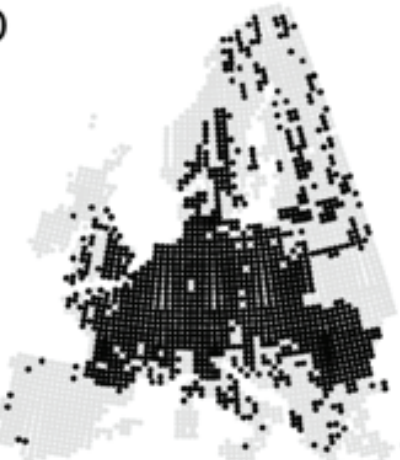

B

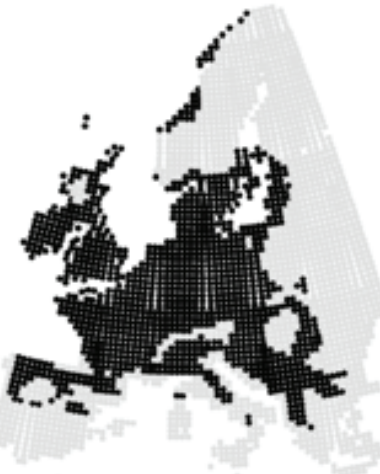

E

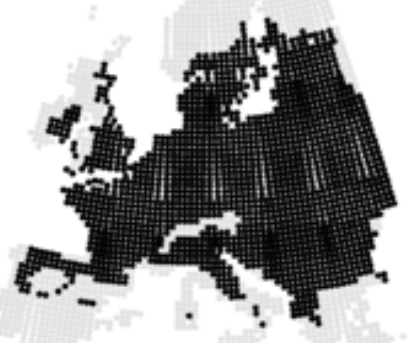

C
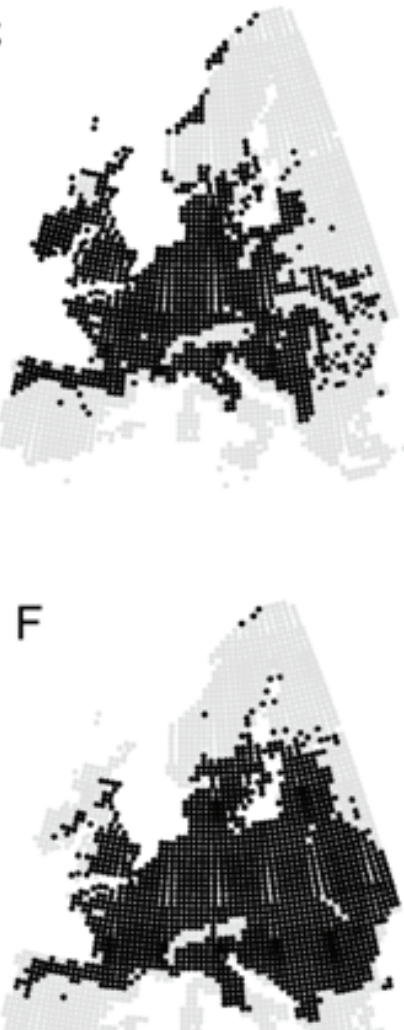

Fig. 2. The distribution of Polygonum persicaria [observed (A), projected based on current climate (B) and projected based on current climate and land use (C)) and Chenopodium polyspermum (observed (D), projected based on current climate (E) and projected based on current climate and land use (F)].

A

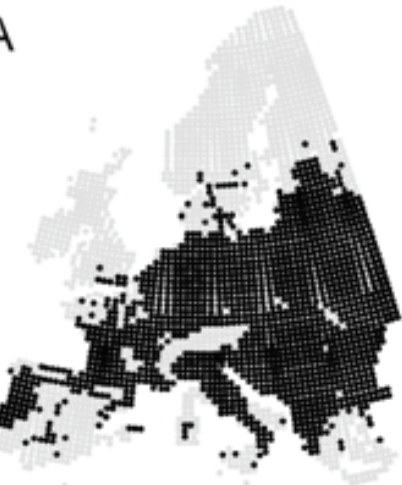

D

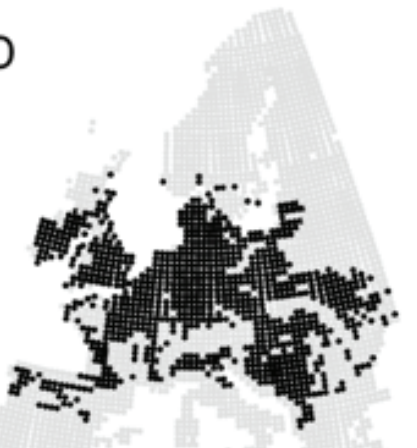

B

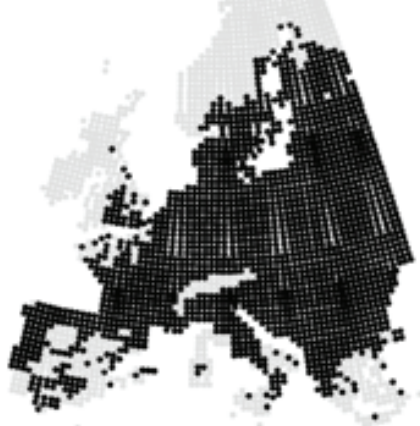

E

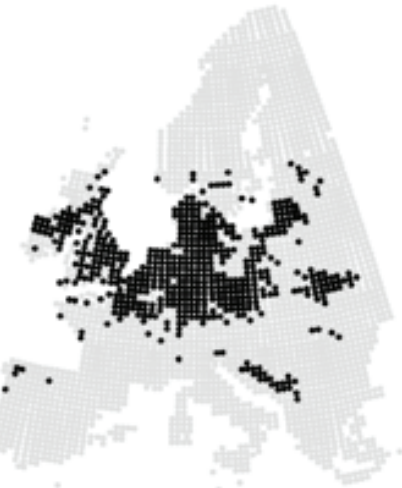

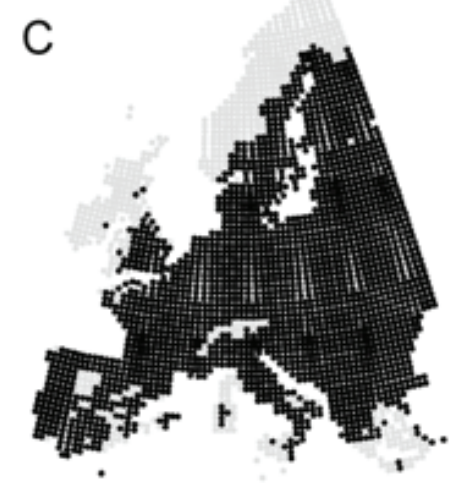

$\mathrm{F}$

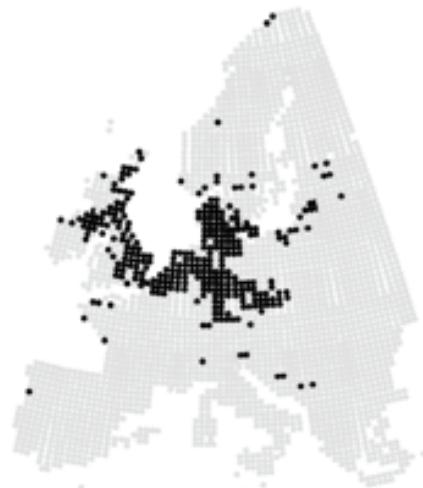

Fig. 3. The projected distribution of Amaranthus retroflexus based on (A) current climate and land use, (B) less severe climate change scenario (HadCM3B2) and land use, (C) more severe climate change scenario (HadCM3A2) and land use and Sinapis arvensis based on (D) current climate and land use, (E) less severe climate change scenario (HadCM3B2) and land use and (F) more severe climate change scenario ( $\operatorname{HadCM} 3 \mathrm{~A} 2)$ and land use. 

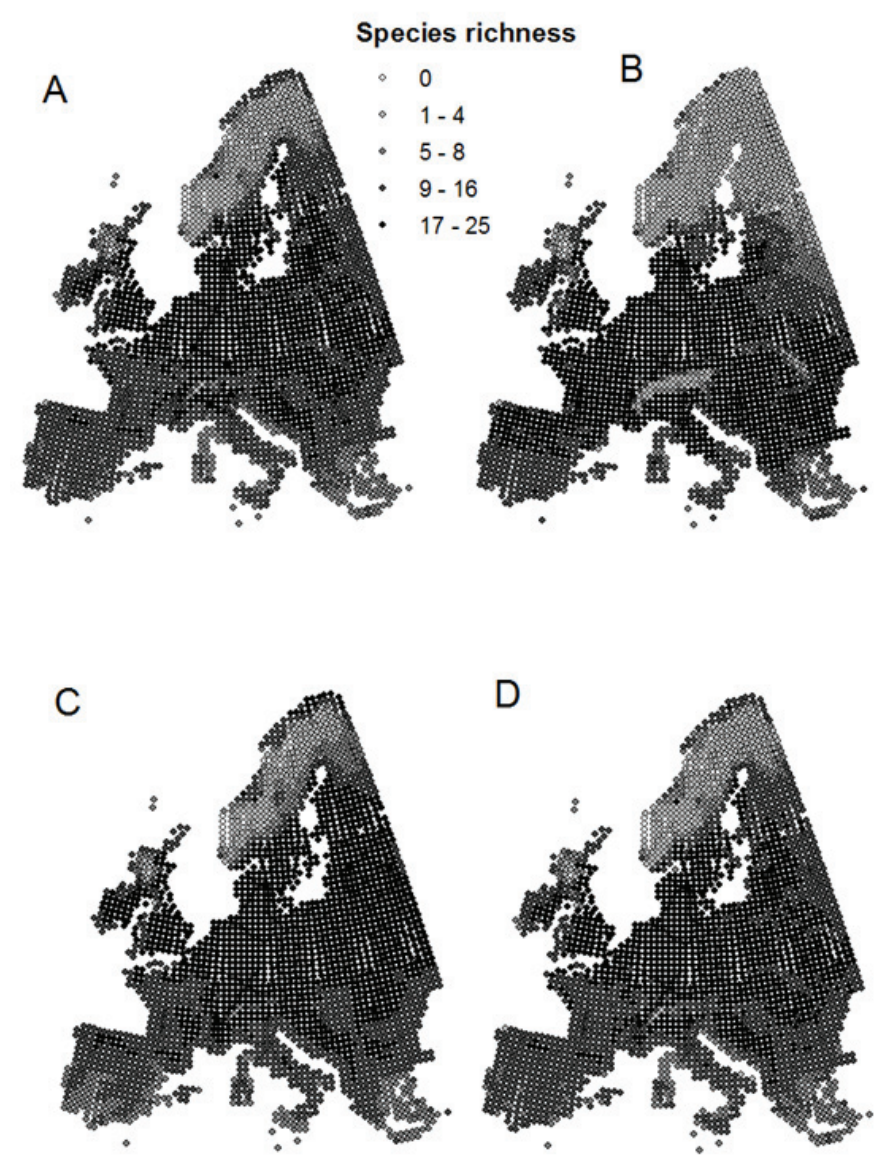

Fig. 4. Projected species richness of the 25 European weed species in 1961-1995 and 2051-2080 based on the following models: current climate (A), current climate and land use (B), more severe climate change scenario (HadCM3A2) (C) and more severe climate change scenario (HadCM3A2) and land use.

A

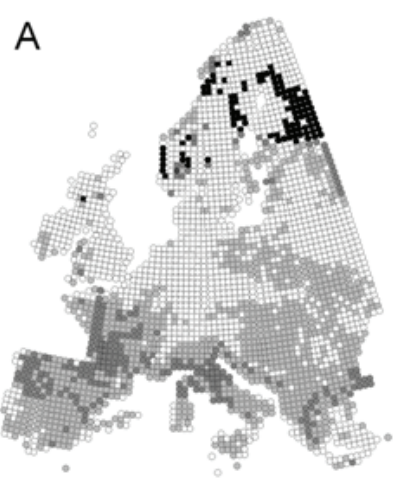

B

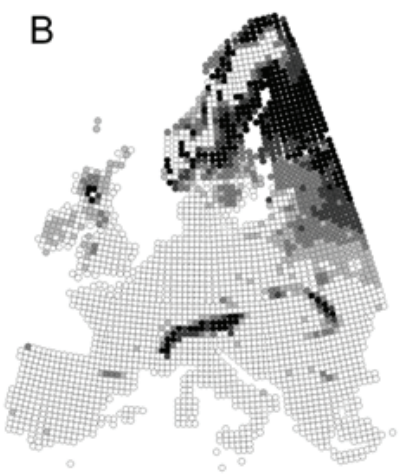

C

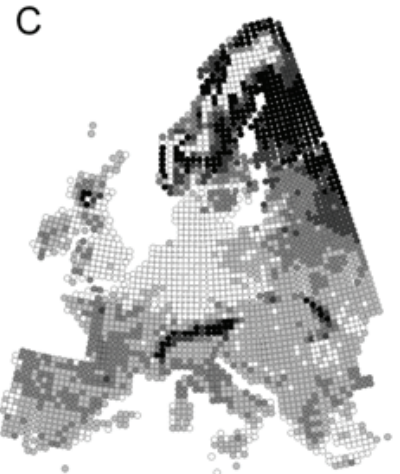

$0-20 \%$

- $21-40 \%$

- $41-60 \%$

- $61-80 \%$

- $81-100 \%$
Fig. 5. Projected species loss (A), gain (B) and turnover (C) of 25 European weed species based on climate-land use models under the assumption of more severe climate change scenario (HadCM3A2). 


\section{Discussion}

Our modeling showed a relatively close fit between climate variables and the distributions of 25 different weed species in Europe, although the species data were only binary and rather coarse-grained. This suggests that weed species in Europe are clearly correlated with climate, and consequently that bioclimate envelope models can provide useful tools to understand the changing geography of potential weed establishment risk in a warming climate. However, using Europe-wide atlas data for plant species, we demonstrated that information on land use in the envelope models provided improved continental-scale projections for species distributions by comparison with projections based on models including only climate parameters (Pearson and Dawson 2003). The contribution of land use to the accuracy of bioclimatic models indicates that the integration of climate and land use information can improve our understanding and model projections of broad-scale biogeographical patterns under climate change (Luoto et al. 2007).

Previous analyses of the potential effect of land use on species distribution models have indicated that land use information often significantly improves the explanatory power of models at local and regional scales (e.g. Stefanescu et al. 2004, Venier et al. 2004). The joint inclusion of climate and land use in the models allows finer spatial resolutions (e.g. Heikkinen et al. 2006, Luoto et al. 2007), suggesting a hierarchical importance of climate and land use in determining the geographical distribution of the species (Pearson et al. 2004). Here, we provide evidence that the explanatory power of land use might also be important on a continental scale, and that the availability of suitable habitats probably plays a role in shaping the dynamic responses of weed species to changes in climate (Hyvönen et al. 2011). The spatial pattern of the landscape and the availability of appropriate habitats may cause species to be absent from climatically suitable areas (Berry et al. 2002, Hampe 2004). Pure climate-driven models are therefore likely to produce incomplete projections when species depart from equilibrium with climate owing to a suite of non-climatic factors (Heikkinen et al. 2006, Araújo and Luoto 2007). The incorporation of land use variables with climatic parameters led to a slight increase in the number of selected predictors. However, when traded-off against the gain in the amount of explained deviance, this moderate increase was found to be meaningful (as reflected by the decreasing AIC (Akaike Information Criteria) values), allowing the weed species distributions to be described with more accuracy (measured by cross-validated AUC values).

We found the establishment risk of weeds in a future climate to vary among regions, species and climate scenarios. Northern Europe, as well as some mountainous regions, was climatically more suitable and southern Europe less suitable for the weed species studied. However, variation among species was substantial, indicating the importance of species-specific responses to climate change. The modelling conducted with a more severe climate scenario resulted in increase in the range sizes of the majority of the species, indicating an increase in the establishment risk of weed species on a European scale.

The regional variation in the establishment risk detected in this study is in accordance with the results of previous modelling conducted with plant distribution data at the European scale (Bakkenes et al. 2002, Thuiller et al. 2005). These previous studies have used the same database (Atlas Florae Europaeae), but larger species assemblages (1397 and 1350 species, respectively) and more climate variables than we used. Despite these differences, the projections for southern and central Europe were surprisingly similar among the studies; for the more northern areas the projections differed more clearly. In our study, the most stable (i.e., lowest species turnover) region was situated in northern Germany, The Netherlands and in the south-eastern UK. A similar finding was reported by Pompe et al. (2008), who used AFE-plant distribution data for modelling future plant distribution in Germany. In previous studies (Bakkenes et al. 2002, Thuiller et al. 2005), the species gain was projected to be high in northern Europe. The same pattern was found in our study, but we obtained slightly higher species gain values. The difference between the results can be explained by the current distribution patterns of species assemblages included in the studies. The 25 species selected for our study represented southern and central European species, whereas the previous studies also included species with broader current distributions.

The patterns of establishment risk projected for individual species were highly variable among species, which appears typical of climate projections (Bakkenes et al. 2002, Skov and Svenning 2004). In general, a decrease in the establishment risk was projected for the species with wide distribution areas, reaching southern Scandinavia but missing from or with scattered occurrence in the Mediterranean region (e.g., Chenopodium rubrum and Rumex obtusifolius), and an increase for the species with more southern distribution patterns (e.g., Fumaria parviflora and Ranunculus arvensis). This pattern was also observed among the species representing the same genus (Papaver dubium vs. P. rhoeas and Chenopodium rubrum vs. C. vulvaria). 
When a more severe climate scenario was applied in the modelling, a more substantial increase or decrease in the establishment risk was projected. Previous studies have accordingly shown the severity of the climate scenario to increase species loss, gain and turnover (Thuiller et al. 2005, Pompe et al. 2008). The majority of species showed a decline in the sizes of suitable climate envelopes compared with the current climate, and in the case of Adonis aestivalis the direction of the prediction changed from positive to negative with increased severity of the climate scenario. We used two different climate scenarios, which represent moderate and intermediate cases among scenarios $\left(2.1^{\circ} \mathrm{C}\right.$ and $2.8^{\circ} \mathrm{C}$ predicted increase in annual mean temperature in 2080 , respectively). The results suggest that even for a moderate climate scenario sizeable changes in the weed establishment risk can be expected to take place in Europe. For some species the changes were minor; therefore, for accurate estimation of the change, species-specific projections are needed due to species-specific responses to climate variables.

We used climate envelope modelling to estimate the establishment risk of weeds. The modelling was based on three climate variables and land use data, which were found to improve the accuracy of the models. In general, the projections provided by climate envelope models should not be taken as precise forecasts of the future and should be interpreted with care (see Heikkinen et al. 2006). Thuiller et al. (2008) discussed the limitations of the plant distribution modelling and listed several ways to progress with the modelling in future, which are applicable also to the modelling of weed species distribution. These challenges include phenotypic plasticity and evolutionary adaptation of weed species (see Clements and Ditommaso 2011), which may violate the assumptions of climate envelope modelling. In the present study, further care should be exercised due to the data being coarse-grained and relatively old for some plant species (Uotila et al. 2005). The accuracy of projections could be improved by using updated species distribution data and by inclusion of soil properties (Coudun et al. 2006) and, especially in the case of weeds, the distribution of suitable cropping systems for the weed species (McDonald et al. 2009). However, suitable climate conditions are the first prerequisite for the establishment of a permanent weed population in a new region, and climate envelope models can provide a reliable prediction of them.

\section{Acknowledgements}

We are indebted to Dr Michael Glemnitz on his help in the selection of weed species for the study, to Dr Tapani Lahti on his help in supplying a copy of the Atlas Florae Europaeae database and to Eeva Lehtonen for drawing the maps. The study was supported financially by the Academy of Finland (TH; the project number 122477).

\section{References}

Araújo, M.B., Cabeza, M., Thuiller, W., Hannah, L. \& Williams, P.H. 2004. Would climate change drive species out of reserves? An assessment of existing reserve-selection methods. Global Change Biology 10: 1618-26.

Araújo, M.B. \& Luoto, M. 2007. The importance of biotic interactions for modelling species distributions under climate change. Global Ecology and Biogeography 16: 743-753.

Bakkenes, M., Alkemade, J.R.M., Ihle, F., Leemans, R. \& Latour, J.B. 2002. Assessing effects of forecasted climate change on the diversity and distribution of European higher plants for 2050. Global Change Biology 8: 390-407.

Berry, P., Dawson, T., Harrison, P. \& Pearson, R.G. 2002. Modelling potential impacts of climate change on the bioclimatic envelope of species in Britain and Ireland. Global Ecology and Biogeography 11: 453-462.

Clements, D.R. \& Ditommaso, A. 2011. Climate change and weed adaptation: can evolution of invasive plants lead to greater range expansion than forecasted? Weed Research 51: 227-240.

Coudun, C., Ge'gout, J-C., Piedallu, C. \& Rameau, J.C. 2006. Soil nutritional factors improve plant species distribution models: an illustration with Acer campestre (L.) in France. Journal of Biogeography 33: 1750-1763.

Fielding, A. \& Bell, J. 1997. A review of methods for the assessment of prediction errors in conservation presence/absence models. Environmental Conservation 24: 38-49.

Glemnitz, M., Radics, L., Hoffmann, J. \& Czimber, G. 2006. Weed species richness and species composition of different arable field types - A comparative analysis along a climate gradient from south to north Europe. Journal of Plant Diseases and Protection, Sonderheft 20: 577-586.

Hampe, A. 2004. Bioclimate envelope models: what they detect and what they hide. Global Ecology and Biogeography 13: 469-476. Hanf, M. 1983. The Arable Weeds of Europe with Their Seedlings and Seeds. Ludwigshafen, Germany: BASF Aktiengeselleschaft. 494 p. Heikkinen, R.K., Luoto, M., Araújo, M.B., Virkkala, R., Thuiller, W. \& Sykes, M. 2006. Methods and uncertainties in bioclimatic envelope modelling under climate change. Progress in Physical Geography 30: 751-777.

Holzner, W. \& Immonen, R. 1982. Europe: an overview. In: Holzner, W. and Numata, N. (eds.). Biology and ecology of weeds. Dr. W. Junk Publishers, The Hague. p. 203-226.

Hyvönen, T., Glemnitz, M., Radics, L. \& Hoffmann, J. 2011. Impact of climate and land use type on the distribution of Finnish casual arable weeds in Europe. Weed Research 51: 201-208. 
IPCC. 2001. Climate Change 2001: The Scientific Basis. Contribution of Working Group I to the Third Assessment Report of the Intergovernmental Panel on Climate Change. , Cambridge:Cambridge University Press. 881 p.

Jalas, J. \& Suominen, J. (eds.). 1972-1994. Atlas Florae Europaeae. Volume 1 (1972), 2 (1973), 3 (1976), 4 (1979), 5 (1980), 6 (1983), 7 (1986), 8 (1989), 9 (1991), 10 (1994). Committee for Mapping the Flora of Europe and Societas Biologica Fennica Vanamo, Helsinki.

Jalas, J., Suominen, J. \& Lampinen, R. (eds.). 1996. Atlas Florae Europaeae. Volume 11. Committee for Mapping the Flora of Europe and Societas Biologica Fennica Vanamo, Helsinki. $310 \mathrm{p}$.

Kriticos, D.J., Yonow, T. \& McFadyen, R.E. 2005. The potential distribution of Chromolaena odorata (Siam weed) in relation to climate. Weed Research 45: 246-254.

Lahti, T. \& Lampinen, R. 1999. From dot maps to bitmaps: Atlas Florae Europaeae goes digital. Acta Botanica Fennica 162: 5-9.

Leathwick, J.R., Whitehead, D. \& McLeod, M. 1996. Predicting changes in the composition of New Zealand's indigenous forests in response to global warming: a modelling approach. Environmental Software 11: 81-90.

Lehmann, A., Overton, J.M. \& Leathwick, J.R. 2002. GRASP: generalized regression analysis and spatial prediction. Ecological Modelling 157: 189-207.

Luoto, M., Virkkala, R. \& Heikkinen, R.K. 2007. The role of land cover in bioclimatic models depends on spatial resolution. Global Ecology and Biogeography 16: 34-42.

Maggini, R., Lehmann, A., Zimmermann, N.E. \& Guisan, A. 2006. Improving generalized regression analysis for the spatial prediction of forest communities. Journal of Biogeography 33: 1729-1749.

McDonald, A., Riha, S., DiTommaso, A. \& DaGaetano, A. 2009. Climate change and the geography of weed damage: Analysis of U.S. maize systems suggests the potential for significant range transformations. Agriculture, Ecosystems \& Environment 130: 131-140.

Milberg, P. \& Andersson, L. 2006. Evaluating the potential northward spread of two grass weeds in Sweden. Acta Agriculturae Scandinavica, Section B - Soil \& Plant Science 56: 91-95.

Mitchell, T.D., Carter, T.R., Jones, P.D., Hulme, M. \& New, M.G. 2004. A comprehensive set of high-resolution grids of monthly climate for Europe and the globe: the observed record (1901-2000) and 16 scenarios (2001-2100). Tyndall Centre Working Paper No. $55,1-30$

New, M., Lister, D., Hulme, M. \& Makin, I. 2002. A high-resolution data set of surface climate over global land areas. Climate Research 21: 1-25.

Patterson, D.T. 1995. Weeds in a changing climate. Weed Science 43: 685-701.

Pearson, R.G. \& Dawson, T.P. 2003. Predicting the impacts of climate change on the distribution of species: are bioclimate envelope models useful? Global Ecology and Biogeography 12: 361-371.

Pearson, R.G., Dawson, T.P. \& Liu, C. 2004. Modelling species distributions in Britain: a hierarchical integration of climate and land-cover data. Ecography 27: 285-298.

Pompe, S., Hanspach, J., Badeck, F., Klotz, S., Thuiller, W. \& Kühn, I. 2008. Climate and land use change impacts on plant distributions in Germany. Biology Letters 4: 564-567.

Potter, K.J.B., Kriticos, D.J., Watt, M.S. \& Leriche, A. 2009. The current and future potential distribution of Cytisus scoparius: a weed of pastoral systems, natural ecosystems and plantation forestry. Weed Research 49: 271-282.

Richardson, D.M., Pyšek, P., Rejmánek, M., Barbour, M.G., Panetta, F.D. \& West, C.J. 2000. Naturalization and invasion of alien plants: concepts and definitions. Diversity and Distribution 6: 93-107.

Root, T.L., Price, J.T., Hall, K.R., Schneider, S.H., Rosenzweig, C. \& Pounds, J.A. 2003. Fingerprints of global warming on wild animals and plants. Nature 421: 57-60.

Sætersdal, M., Birks, H.J.B. \& Peglar, S.M. 1998. Predicting changes in Fennoscandian vascular-plant richness as a result of future climatic change. Journal of Biogeography 25: 111-122.

Schroeder, D., Mueller-Schaerer, H. \& Stinson, C.S.A. 1993. A European weed survey in 10 major crop systems to identify targets for biological control. Weed Research 33: 449-458.

Skov, F. \& Svenning, J-C, 2004. Potential impact of climatic change on the distribution of forest herbs in Europe. Ecography 27 : 366-380.

Stefanescu, C., Herrando, S. \& Paramo, F. 2004. Butterfly species richness in the north-west Mediterranean Basin: the role of natural and human-induced factors. Journal of Biogeography 31: 905-915.

Thuiller, W. 2003. BIOMOD - optimizing predictions of species distributions and projecting potential future shifts under global change. Global Change Biology 9: 1353-62.

Thuiller, W., Lavorel, S., Araújo, M.B., Sykes, M.T. \& Prentice, I.C. 2005. Climate change threats to plant diversity in Europe. Proceedings of the National Academy of Sciences, USA 102: 8245-8250.

Thuiller, W., Albert, C., Araújo, M.B., Berry, P.M., Cabeza, M., Guisan, A., Hickler, T., Midgley, G.F., Paterson, J., Schurr, F.M., Sykes, M.T. \& Zimmermann, N.E. 2008. Predicting global change impacts on plant species' distributions: Future challenges. Perspectives in Plant Ecology, Evolution and Systematics 9: 137-152.

Uotila, P., Lahti, T. \& Suominen, J. 2005. Erfahrung über die langjährige Kartierung von Pflanzen: Atlas Florae Europaeae. Hoppea 66: 119-132. (in German).

Venier, L.A., Pearce, J., McKee, J.E., McKenney, D.W. \& Niemi, G.J. 2004. Climate and satellite derived land cover for predicting breeding bird distribution in the Great Lakes Basin. Journal of Biogeography 31: 315-331.

Williams, G.H. 1982. Elsevier's dictionary of weeds of Western Europe.Amsterdam, The Netherlands: Elsevier Scientific Publishing Company. 320 p. 


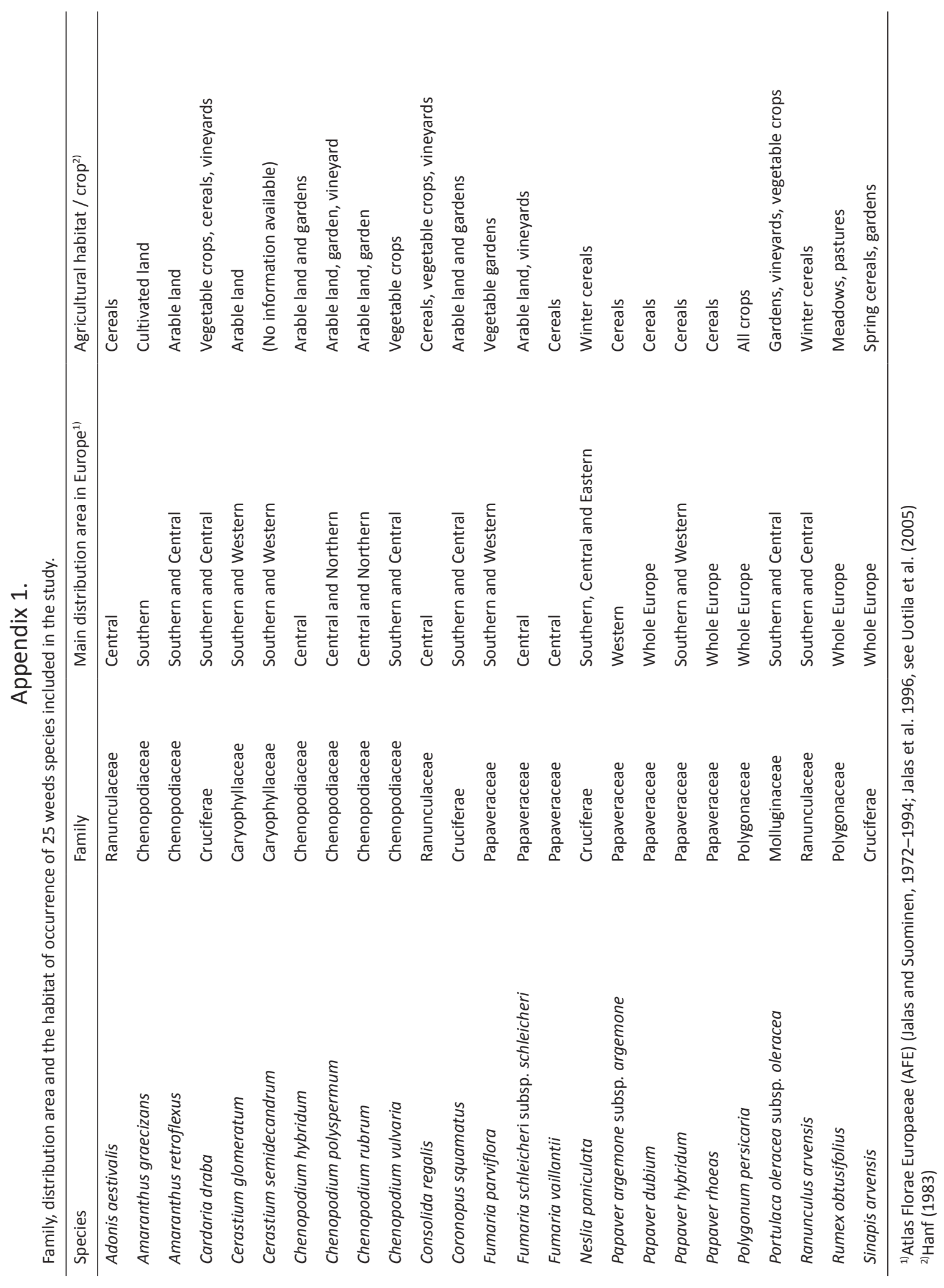




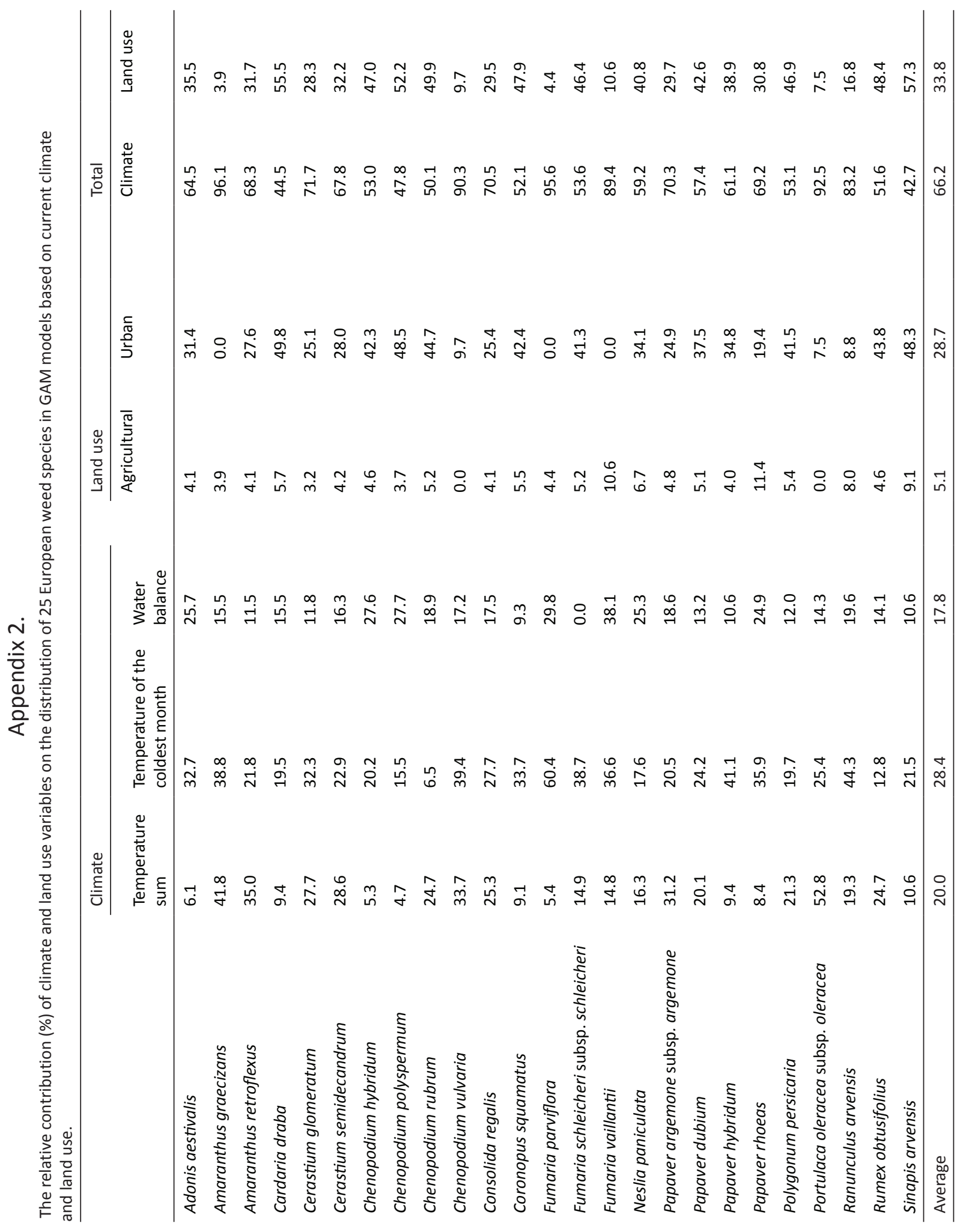

